Project 1021841

\title{
Anaerobic U(IV) Bio-oxidation and the Resultant Remobilization of Uranium in Contaminated Sediments
}

\author{
Coates, John D. \\ University of California, Berkeley
}

RESULTS TO DATE: A proposed strategy for the remediation of uranium (U) contaminated sites is based on immobilizing $\mathrm{U}$ by reducing the oxidized soluble $\mathrm{U}, \mathrm{U}(\mathrm{VI})$, to form a reduced insoluble end product, $\mathrm{U}(\mathrm{IV})$. Due to the use of nitric acid in the processing of nuclear fuels, nitrate is often a co-contaminant found in many of the environments contaminated with uranium. Recent studies indicate that nitrate inhibits $U(V I)$ reduction in sediment slurries. However, the mechanism responsible for the apparent inhibition of $\mathrm{U}(\mathrm{VI})$ reduction is unknown, i.e. preferential utilization of nitrate as an electron acceptor, direct biological oxidation of $\mathrm{U}(\mathrm{IV})$ coupled to nitrate reduction, and/or abiotic oxidation by intermediates of nitrate reduction. Recent studies indicates that direct biological oxidation of $U(I V)$ coupled to nitrate reduction may exist in situ, however, to date no organisms have been identified that can grow by this metabolism. In an effort to evaluate the potential for nitrate-dependent bio-oxidation of U(IV) in anaerobic sedimentary environments, we have initiated the enumeration of nitrate-dependent U(IV) oxidizing bacteria. Sediments, soils, and groundwater from uranium $(U)$ contaminated sites, including subsurface sediments from the NABIR Field Research Center (FRC), as well as uncontaminated sites, including subsurface sediments from the NABIR FRC and Longhorn Army Ammunition Plant, Texas, lake sediments, and agricultural field soil, sites served as the inoculum source. Enumeration of the nitratedependent $\mathrm{U}(\mathrm{IV})$ oxidizing microbial population in sedimentary environments by most probable number technique have revealed sedimentary microbial populations ranging from $9.3 \times 101-2.4 \times 103$ cells $(\mathrm{g}$ sediment)-1 in both contaminated and uncontamined sites. Interestingly uncontaminated subsurface sediments (NABIR FRC Background core FB618 and Longhorn Texas Core BH2-18) both harbored the most numerous nitrate-dependent U(IV) oxidizing population $2.4 \times 103$ cells (g sediment)- 1 . The nitratedependent $U(I V)$ oxidizing microbial population in groundwaters is less numerous ranging from 0 cells mL-1 (Well FW300, Uncontaminated Background NABIR FRC) to $4.3 \times 102$ cells mL-1 (Well TPB16, Contaminated Area 2 NABIR FRC). The presence of nitrate-dependent U(IV) oxidizing bacteria supports our hypothesis that bacteria capable of anaerobic U(IV) oxidation are ubiquitous and indigenous to sedimentary and groundwater environments. Libraries of small-subunit rRNA clones were constructed from the lowest dilution MPN series to phylogenetically profile the U(IV)-oxidizing microbial communities. Clone libraries initiated from agricultural field soil revealed primary members of the nitrate-dependent U(IV) oxidizing microbial community similar to the gamma and beta subclass of the Proteobacteria as well as Gram Positive bacteria. The primary members of the microbial community associated with the nitratedependent U(IV) oxidization MPN series initiated from freshwater lake sediment were identified as most similar to known organisms associated with the alpha, beta, and gamma subclasses of the Proteobacteria. Among members of the Betaproteobacteria that were identified in both terrestrial environments were the known nitrate-dependent Fe(II) oxidizing genera, Dechloromonas sp., Azospira sp., and Chromobacterium sp. MPN enumeration series initiated from sediment collected from the background site of the NABIR FRC (10-4 dilution) resulted in clones most similar to Gammaproteobacteria, Pseudomonas sp., and Betaproteobacteria, Janthinobacterium lividum, Duganella sp., and Neisseria sp.. The clone library created from the MPN series initiated from groundwater collected from Area 1, NABIR FRC (10-4 dilution), identified clones most similar to Gammaproteobacteria, Escherichia coli, Shigella sp. and Samonella sp., and Betaproteobacteria, Stenotrophomonas sp.. However, the role that these microorganisms identified in the MPN series play in nitrate-dependent U(IV) oxidation is currently unknown as a nitrate-dependent $\mathrm{U}(\mathrm{IV})$-oxidizing isolate has eluded us to date. In addition to the enumeration of nitrate-dependent $\mathrm{U}(\mathrm{IV})$ in environmental samples, we have begun screening a known $\mathrm{U}(\mathrm{VI})$-reducing bacterium (Shewanella oneidensis strain MR-1) as well as nitratedependent Fe(II) oxidizing bacteria isolated in our laboratory (strain 2002 1, and strain COL-7, 99\% similar to Azospira suillium) for the metabolic ability to oxidize U(IV) coupled to nitrate reduction. These bacteria tested to date are incapable of oxidizing $U(I V)$ coupled to nitrate reduction. This result is consistent with a previous result reported in our laboratory indicating that although A. suillium was 
capable of oxidizing Fe(II) coupled to nitrate reduction, U(IV) was not oxidized in a similar manner 2. These results suggest that anaerobic $U(I V)$ bio-oxidation is not necessarily synonymous with anaerobic metal bio-oxidation or bio-reduction. Geobacter metallireducens, an organism more readily recognized for its ability to grow by $\mathrm{Fe}(\mathrm{III})$ or $\mathrm{U}(\mathrm{VI})$ reduction, was previously shown to be alternatively capable of oxidizing $\mathrm{U}(\mathrm{IV})$ with nitrate as the electron acceptor 3 . To date this is the only organism described known to be capable of nitrate-dependent U(IV) oxidation. As such $\mathrm{G}$. metallireducens served as the model bacterium in our initial studies to determine the specific enzymes associated with the anaerobic biooxidation of U(IV). Expressed protein content of cells grown under nitrate reducing conditions in the presence and absence of $\mathrm{U}(\mathrm{IV})$. Electrophoresis of the total protein content of cell lysates prepared from these cultures revealed the selective expression of cytochromes associated with this metabolism. These preliminary results would suggest that U(IV) oxidation is mediated by a inducible enzyme system. Together these results indicated that nitrate-dependent $U(I V)$ oxidizing bacteria are prevelant in the environment and that this metabolism could contribute to bio-oxidation of U(IV). In light of the recent observation that $\mathrm{U}(\mathrm{IV})$ can be abiotically oxidized by biogenic Fe(III) oxides4, we also investigated the oxidizing capacity of biogenic Fe(II) oxides formed by A. suillum via nitrate-dependent $\mathrm{Fe}$ (II) oxidation under non-growth conditions. Previously we had demonstrated the biogenic Fe(III) oxides formed under non-growth conditions resulted in an amorphous Fe(III) oxide precipitate 5. In contrast to previous reports, biogenic formation of amorophous Fe(III) oxides, oxidation of ca. $9 \mathrm{mM} \mathrm{Fe}$ (II) by A. suillum did not result in the oxidation of $\mathrm{U}(\mathrm{IV})$. .

DELIVERABLES: References Cited 1. Weber, K. A. et al. Anaerobic Nitrate-Dependent Iron(II) Oxidation by a Novel, Mesophilic, Neutrophilic Bacterium, strain 2002. submitted Appl Environ Microbiol (2004). 2. Lack, J. G. et al. Immobilization of Radionuclides and Heavy Metals through Anaerobic Bio-Oxidation of Fe(II). Appl Environ Microbiol 68, 2704-2710 (2002). 3. Finneran, K. T., Housewright, M. E. \& Lovley, D. R. Multiple influences of nitrate on uranium solubility during bioremediation of uranium-contaminated subsurface sediments. Environmental Microbiology 4, 510-516 (2002). 4. Senko, J. M., Mohamed, Y., Dewers, T. A. \& Krumholz, L. R. Role for Fe(III) minerals in nitrate-dependent microbial U(IV) oxidation. Environ Sci Technol 39, 2529-2536 (2005). 5. Lack, J. G., Chaudhuri, S. K., Chakraborty, R., Achenbach, L. A. \& Coates, J. D. Anaerobic biooxidation of Fe(II) by Dechlorosoma suillum. Microb Ecol 43, 424-431 (2002). 